\title{
The IA-2 gene family: homologs in Caenorhabditis elegans, Drosophila and zebrafish
}

\author{
T. Cai ${ }^{1}$, M. W. Krause ${ }^{2}$, W.F. Odenwald ${ }^{3}$, R. Toyama ${ }^{4}$, A. L. Notkins ${ }^{1}$ \\ ${ }^{1}$ Experimental Medicine Section, Oral Infection and Immunity Branch, National Institute of Dental and Craniofacial Research, \\ National Institutes of Health (NIH), Bethesda, Maryland, USA \\ ${ }^{2}$ Section of Developmental Biology, Laboratory of Molecular Biology, National Institute of Diabetes, Digestive and Kidney \\ Diseases, NIH, Bethesda, Maryland, USA \\ ${ }^{3}$ The Neurogenetics Unit, Laboratory of Neurochemistry, National Institute of Neurological Disorders and Stroke, NIH, \\ Bethesda, Maryland, USA \\ ${ }^{4}$ Laboratory of Molecular Genetics, National Institute of Child Health and Human Development, NIH, Bethesda, Maryland, USA
}

\section{Abstract}

Aims/hypothesis. IA-2 and IA-2 $\beta$ are major autoantigens in Type I (insulin-dependent) diabetes mellitus and are expressed in neuroendocrine tissues including the brain and pancreatic islets of Langerhans. Based on sequence analysis, IA- 2 and IA- $2 \beta$ are transmembrane protein tyrosine phosphatases but lack phosphatase activity because of critical amino acid substitutions in the catalytic domain. We studied the evolutionary conservation of $I A-2$ and $I A-2 \beta$ genes and searched for homologs in non-mammalian vertebrates and invertebrates.

Methods. IA-2 from various species was identified from EST sequences or cloned from cDNA libraries or both. Expression in tissues was determined by transfection and in situ hybridization.

Results. We identified homologs of $I A-2$ in C. elegans, Drosophila, and zebrafish which showed 46, 58 and $82 \%$ identity and 60,65 and $87 \%$ similarity, respectively, to the amino acids of the intracellular do- main of human IA-2. Further studies showed that IA-2 was expressed in the neural tissues of the three species. Comparison of the genomic structure of the intracellular domain of human $I A-2$ with that of human $I A-2 \beta$ showed that they were nearly identical and comparison of the intron-exon boundaries of Drosophila $I A-2$ with human $I A-2$ and $I A-2 \beta$ showed a high degree of relatedness.

Conclusion/Interpretation. Based on these findings and sequence analysis of $I A-2$ homologs in mammals, we conclude that there is an $I A-2$ gene family which is a part of the larger protein tyrosine phosphatase superfamily. The $I A-2$ and $I A-2 \beta$ genes represent two distinct subgroups within the $I A-2$ family which originated over 500 million years ago, long before the development of the pancreatic islets of Langerhans. [Diabetologia (2001) 44: 81-88]

Keywords C. elegans, Drosophila, zebrafish, IA-2, insulin-dependent diabetes mellitus
IA-2 is a major autoantigen in Type I (insulin-dependent) diabetes mellitus [1-3]. Approximately $70 \%$ of newly diagnosed Type I diabetic patients have autoantibodies to IA-2. These autoantibodies appear years before clinical symptoms have developed and have become predictive markers for identifying peo-

Received: 26 May 2000 and in revised form: 4 September 2000

Corresponding author: Dr A. L. Notkins, National Institutes of Health, Building 30/Room 121, 30 Convent Dr. MSC 4322, Bethesda, Maryland 20892-4322, USA

Abbreviations: GFP, green fluorescent protein; PTP, proteintyrosine phosphatase ple with a high risk of developing Type I diabetes. People who have autoantibodies to IA-2 and glutamic acid decarboxylase (GAD) are at an even higher risk for disease. Over one-half of the people with autoantibodies to IA-2 and GAD are likely to develop Type I diabetes within 5 years and an even higher percentage within 10 years [4].

Sequence analysis indicates that IA-2 is a member of the protein tyrosine phosphatase (PTP) family [1]. It has an intracellular domain which contains a single PTP-like core sequence, a transmembrane region and an extracellular domain. The PTP core sequence of IA-2, however, has several amino acids substitutions at conserved sites $\left(\mathrm{Ala}^{911} \rightarrow \mathrm{Asp}\right.$ and $\left.\mathrm{Asp}^{877} \rightarrow \mathrm{Ala}\right)$ 


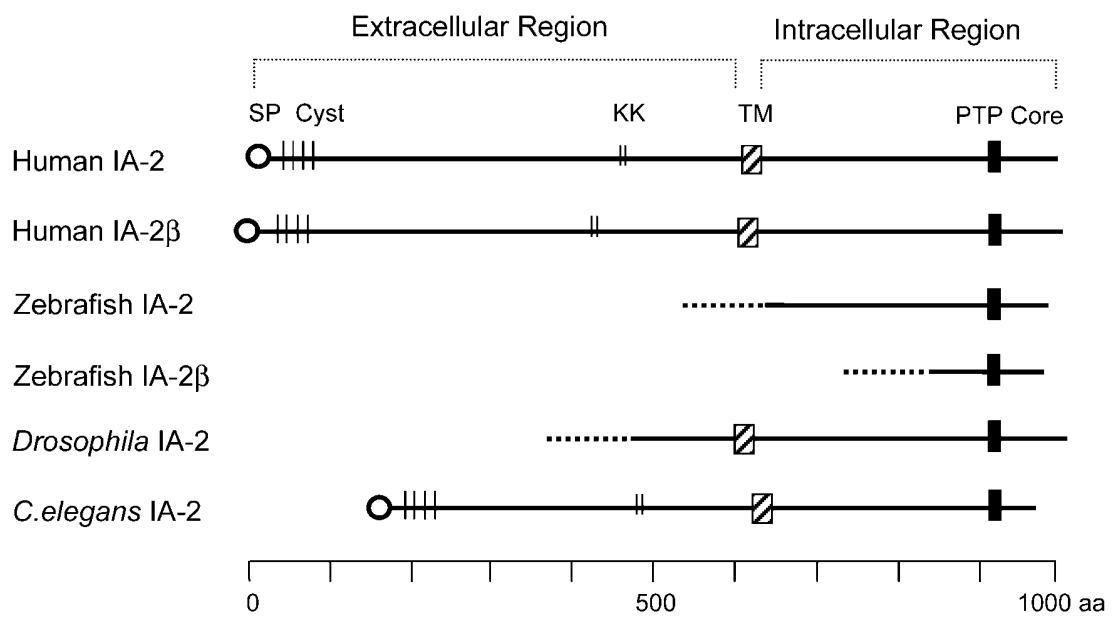

Fig. 1. Diagrammatic representation of IA-2 proteins: signal peptide (SP); cysteine motif (Cyst); potential dibasic amino acid cleavage sites (KK); transmembrane region (TM); protein tyrosine phosphatase core (PTP). Dash lines represent incomplete sequences

known to be critical for enzymatic activity. The IA-2 autoantigen fails to show phosphatase activity when tested with a variety of PTP substrates but enzyme activity can be restored by changing these two amino acids back to the conserved sequence $[2,5,6]$. The IA-2 autoantigen is expressed in neuroendocrine tissues, particularly in the brain and pancreatic islets of Langerhans and is present in secretory granule membranes $[7,8]$. The function of this protein is not known.

The closest relative to IA- 2 is IA- $2 \beta[7,9,10]$, also known as phogrin [7]. It is $74 \%$ identical to the intracellular domain and $26 \%$ identical to the extracellular domain of IA-2 and has a similar neuroendocrine tissue distribution. Patients with Type I diabetes also develop autoantibodies to IA- $2 \beta$ but the frequency is somewhat lower than to IA-2 $[9,10]$. Often autoantibodies that recognize IA- $2 \beta$ also recognize IA-2 but only about $50 \%$ of the autoantibodies that react with IA- 2 will also react with IA- $2 \beta$. In both IA-2 and IA- $2 \beta$, the autoantibodies react exclusively with the intracellular domains and show no reactivity with the extracellular domains [11,12].

Homologs of $I A-2$ have been identified in several mammalian species $[1,5,13-16]$. We searched for evolutionary relatives of $I A-2$ in non-mammalian vertebrates (zebrafish) and in invertebrates (Caenorhabditis elegans and Drosophila melanogaster). Our studies show that $I A-2$ and $I A-2 \beta$ are members of an ancient gene family.

\section{Materials and methods}

Sequencing of cDNA Clones. The nucleotides sequence of each clone was determined in both directions by the dideoxynucleotide chain termination method using the Sequence Version 2.0 sequencing kit (Biochemical Corporation, Cleveland, Ohio, USA).

C. elegans. A 3282-bp fragment (cosmid B0244, provided by the Sanger Center, UK), 5' upstream from the methionine start site, containing the promoter fragment, was PCR-amplified using primers (sense, 5'-TCTGCAGCCT GCCTG TGCCA ACTTA CC-3'; antisense, 5'-TTGGC CATGC GGATG ACACA GAGAT GC-3') and inserted into the $p s t I-M s c I$ vector pPD 95.69 (A. Fire, G. Seydoux, J. Ahnn, and S. Q. Xu, personal communication). This construct, containing a nuclear localization signal (NLS) was linked to the green fluorescent protein (GFP) gene. In other constructs, the NLS was removed with $K p n I$ and $M s c I$ and full-length $C$. elegans $I A-2$ cDNA was inserted. To overexpress $C$. elegans IA-2 in vivo, a 2.4-kb fulllength cDNA was released from clone $y k 27 f 7$ with $M s c I$ and ApaI, and subcloned into a pPD49.83 vector driven by heat shock promoter (provided by Dr. A. Fire).

Drosophila. The mRNA expression of $I A-2$ was measured by using a digoxigenin-labeled riboprobe $[17,18]$ containing a 1.3 $\mathrm{kb} I A-2$ fragment linearized with NotI from clone HL02546.

Zebrafish. The mRNA expression was analysed by in situ hybridization using a riboprobe containing the entire $I A-2$ or $I A-2 \beta$ sequences. Double staining for $I A-2$ and Krox-20 gene expression was carried out as described previously [19].

Chromosome Mapping and Genomic Structure. Zebrafish chromosomal mapping was carried out using a recently developed radiation hybrid panel [20] and two paired-primers designed from 3'-UTR region of zebrafish IA-2 (forward, 5'CTGTCTGTATGCTGGAA-3'; reverse, 5'-GGCTGCACAA GACAGTAA-3') and zebrafish IA- $\beta$ (forward, 5'CCCTGCTCCTATAACACTAACC-3'; reverse, 5'-CACATGGTTC ATTCTGTACG-3'). The PCR conditions were as described [20]. The intron-exon boundaries of human $I A$ $2 \beta$ and Drosophila IA-2 were determined from recently entered sequences in the GenBank (accession numbers: human IA-2 $\beta$, A005 481 and AC006321; Drosophila IA-2, AC013239 and AC008228).

Phylogenetic Tree. A stretch of 393 bp or the corresponding $C$ terminal 131 aa predicted protein sequence was aligned and a 
human IA-2

bovine IA-2

rat IA-2

mouse IA-2

human IA- $2 \beta$

macaca IA-2 $\beta$

rat $I A-2 \beta$

mouse IA- $2 \beta$

zebrafish IA- $2 \beta$ zebrafish IA-2

Drosophila IA-2

C.elegance IA-2
693 HMILAYMEDHLRNRDRLAKEWQALCAYQAEPNTCATAQ-GEGNIKKNRHPDFLPYDHARIKLKVESSPSRS

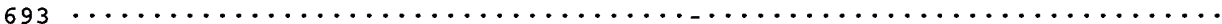

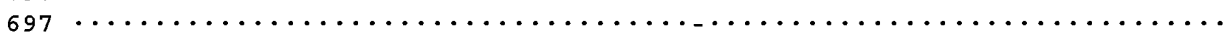

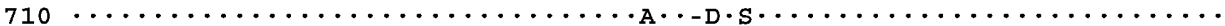

$700 \cdots \mathrm{S} \cdots \cdots \mathrm{K} \cdot \mathrm{KN} \cdot \mathrm{E} \cdots \mathrm{E} \cdot \mathrm{M} \cdot \mathrm{SSSF} \cdot \cdots \mathrm{R} \cdot \mathrm{E} \cdot \mathrm{VP} \cdots \mathrm{SLAV} \cdot \mathrm{T} \cdot \cdots \mathrm{S} \cdot \mathrm{VL} \cdot \mathrm{A} \cdot \mathrm{N} \cdot \mathrm{H} \cdot \mathrm{H} \cdot$

$727 \cdots \mathrm{S} \cdots \cdots \mathrm{K} \cdot \mathrm{KN} \cdot \mathrm{E} \cdots \mathrm{E} \cdot \mathrm{K} \cdot \mathrm{SSLV} \cdot \mathrm{S} \cdot \mathrm{E} \cdot \mathrm{VP} \cdots \mathrm{SLAV} \cdot \mathrm{T} \cdot \mathrm{S} \cdot \mathrm{VL} \cdot \mathrm{A} \cdot \mathrm{N} \cdot \mathrm{H} \cdot \mathrm{H} \cdot$

$718 \cdots \cdots \cdots \cdot \mathrm{K} \cdot \mathrm{KN} \cdot \mathrm{E} \cdot \mathrm{E} \cdot \cdots \cdots \mathrm{DSSLV} \cdot \mathrm{K} \cdot \mathrm{E} \cdot \mathrm{AP} \cdot \mathrm{SLAV} \cdot \mathrm{T} \cdot \mathrm{S} \cdot \mathrm{L} \cdot \mathrm{S} \cdot \mathrm{N} \cdot \mathrm{H} \cdot \mathrm{N} \cdot$

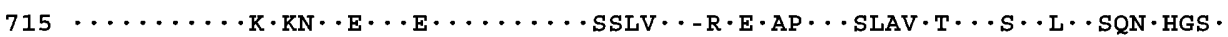

1

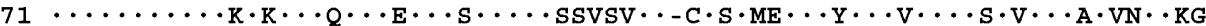

$201 \mathrm{~N} \cdot \mathrm{V} \cdot \mathrm{SN} \cdots \cdot \mathrm{KG} \cdot \mathrm{QR} \cdot \mathrm{E} \cdot \cdots \mathrm{R} \cdot \mathrm{E} \cdots \mathrm{S} \cdot \mathrm{RE} \cdot \mathrm{ASQPQCAGL} \cdots \mathrm{PGAP} \cdots \cdot \mathrm{S} \cdot \mathrm{VV} \cdot \mathrm{NHLANAEGL}$ $486 \cdot \mathrm{VV} \cdot \mathrm{NFLQEY} \cdot \mathrm{SEPTKIEAQ} \cdot \mathrm{NGIKD} \cdot \mathrm{RN} \cdot \mathrm{ER} \cdot \mathrm{KTK} \cdot-\cdot-\cdot \mathrm{KFASQ} \cdot \cdot \mathrm{TILP}-\mathrm{F} \cdot \mathrm{DNIVDIDGKTAENED}$

human IA-2
bovine IA-2
rat IA-2
mouse IA-2
human IA-2 $\beta$
macaca IA- $2 \beta$
rat IA-2 $\beta$
mouse IA-2 $\beta$
zebrafish IA-2 $\beta$
zebrafish IA-2
Drosophila IA-2
C.elegance IA-2

human IA-2

bovine IA-2

rat IA-2

mouse IA-2

human IA-2 $\beta$

macaca IA-2 $\beta$

rat IA- $2 \beta$

mouse IA- $2 \beta$

zebrafish IA-2 $\beta$

zebrafish IA-2

Drosophila IA-2

C.elegance IA-2

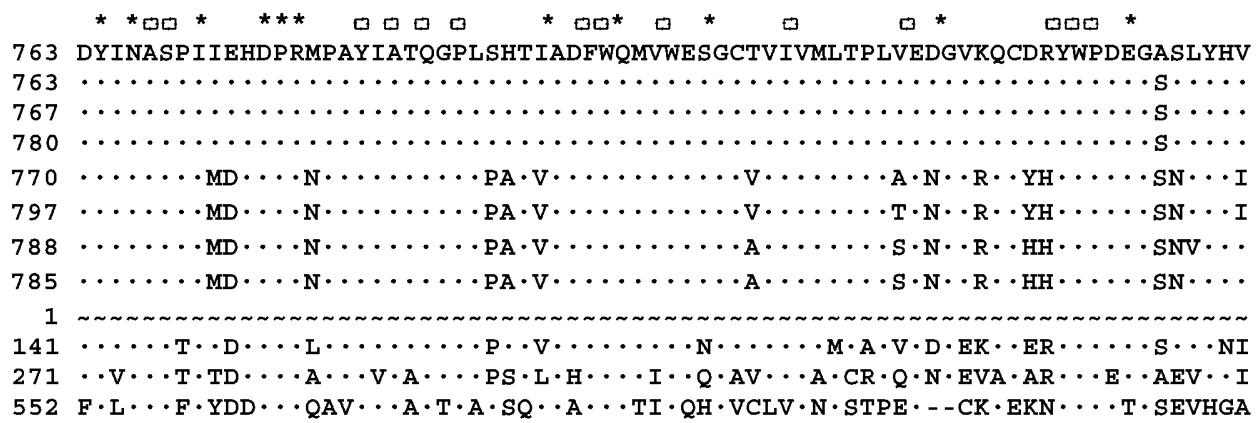

* $* * * * * * * * * * * \square^{*} \square * * * \quad * * \square * \square \square * * * \square \quad \square \quad * \square^{*} * * \square^{* * * * * *}$ 835 YEVNLVSEHIWCEDFLVRSFYLKNVQTQETRTLTQFHFLSWPAEGTPASTRPLLDFRRKVNKCYRGRSCPII

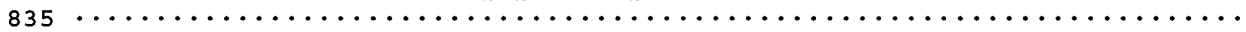

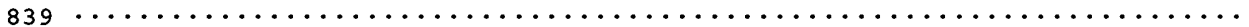

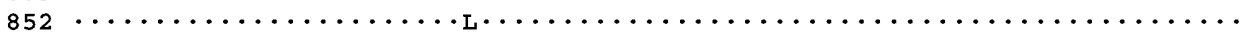

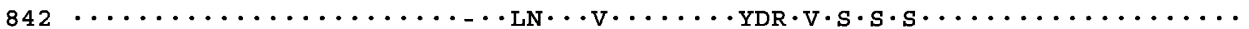

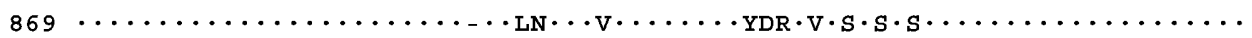

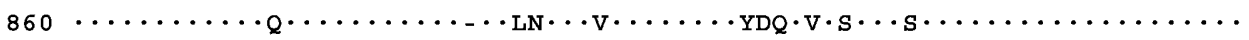

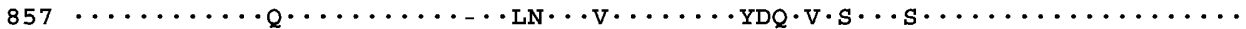

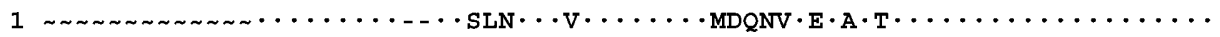

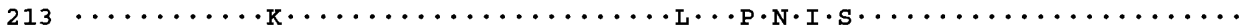

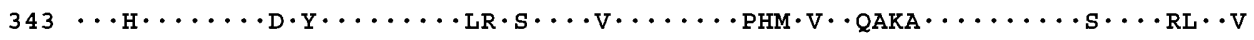

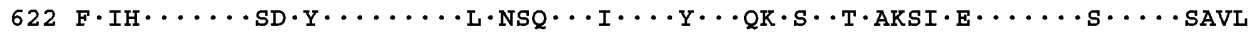

human IA-2
bovine IA-2
rat IA-2
mouse IA-2
human IA-2 $\beta$
macaca IA-2 $\beta$
rat IA-2 $\beta$
mouse IA-2 $\beta$
zebrafish IA-2 $\beta$
zebrafish IA-2
Drosophila IA-2
C.elegance IA-2

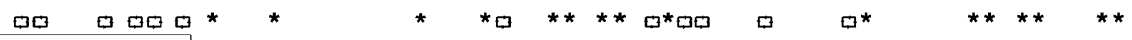

\begin{tabular}{|c|c|}
\hline 07 & VHCSDGAGRTGTYILIDMVLNRMAKGVKEIDIAATLEHVRDQRPGLVRSKDQFEFALTAVAEEVNAILKALPQ \\
\hline & 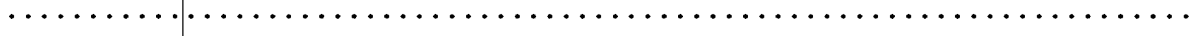 \\
\hline & 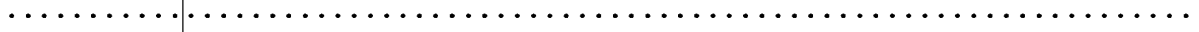 \\
\hline & $\cdots$ \\
\hline & 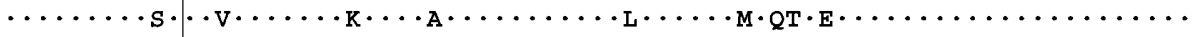 \\
\hline & 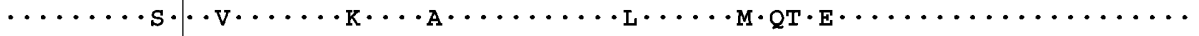 \\
\hline & $\cdots \mathrm{v} \cdots \cdots \cdot \mathrm{K} \cdots \mathrm{A}_{\mathrm{A}} \cdots \cdots \cdots \cdots \mathrm{L}_{\mathrm{L}} \cdots \mathrm{M} \cdot \mathrm{QT} \cdot \mathrm{E} \cdot \ldots \ldots \ldots \ldots$ \\
\hline & $\cdots \mathrm{v} \cdots \cdots \cdot \mathrm{K} \cdots \cdots \mathrm{A} \cdot \cdots \cdots \cdots \cdot \mathrm{L} \cdots \cdots \mathrm{M} \cdot \mathrm{QT} \cdot \mathrm{E} \cdot \cdots \cdots \cdots \cdots$ \\
\hline & $\cdots \cdots \mathrm{K} \cdot \cdots \mathrm{A} \cdots \cdots \cdot \mathrm{L} \cdot \cdots \mathrm{S} \cdot \mathrm{M} \cdot \mathrm{QT} \cdot$ \\
\hline & 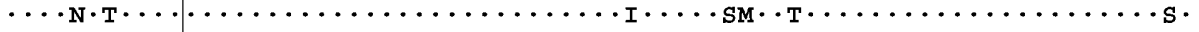 \\
\hline & $\cdots \mathrm{G} \cdot \mathrm{A} \cdots \cdots \mathrm{V} \cdot \cdots \mathrm{L} \cdot \mathrm{L} \cdot \mathrm{E} \cdot \mathrm{N} \cdot \mathrm{AR}_{\mathrm{A}} \cdots \cdots \cdot \mathrm{L} \cdots \mathrm{ASV}_{\mathrm{A}} \mathrm{AT}$ \\
\hline & $\cdots \mathrm{SW} \cdot \mathrm{s} \cdots \cdot \mathrm{V} \cdot \mathrm{CAV} \cdot \mathrm{VLCA} \cdot \mathrm{LLR} \cdot \mathrm{IRQ} \cdot \mathrm{VV} \cdot \cdot \mathrm{V} \cdot \mathrm{L} \cdots \mathrm{D} \cdot \mathrm{M} \cdot \mathrm{ATG} \cdot \cdots \mathrm{KLVYGC} \cdot \mathrm{Q} \cdot \cdots \mathrm{HL} \cdot \mathrm{SIAT}$ \\
\hline
\end{tabular}

Fig. 2. Multiple sequence alignment of the intracellular PTPlike domain of members of the IA-2 family. Residues from the PTP signature motifs of IA-2 members are boxed. Residues conserved in all members of the IA-2 family are marked with a star (*) and residues conserved when compared to an enzymatically active PTP (i.e., LAR, D1 domain) are marked with an open box. (dots) identical amino acids; (wave-like line) incomplete sequence; (dashed line) gap for sequence alignment phylogenetic analysis was carried out using Pileup, Distances (i.e., unweighted pair group method) and Growtree programs of the Genetics Computer Group package (GCG, Wisconsin Package Version 10.1, Madison, Wis., USA).

\section{Results}

C. elegans. The nucleotide sequence of human $I A-2$ was used to search a $C$. elegans EST database. At least thirteen ESTs were found that showed a high de- 
Table 1. Chromosomal localization and degree of relatedness to human IA-2

\begin{tabular}{|c|c|c|c|c|c|c|c|c|c|}
\hline \multirow[t]{2}{*}{$\begin{array}{l}\text { Sub- } \\
\text { family }\end{array}$} & \multirow[t]{2}{*}{ Species } & \multirow[t]{2}{*}{$\begin{array}{l}\text { Chromo- } \\
\text { some } \\
\text { locus }\end{array}$} & \multirow[t]{2}{*}{$\begin{array}{l}\text { Amino } \\
\text { acid } \\
\text { residues }\end{array}$} & \multicolumn{2}{|c|}{$\begin{array}{l}\text { Intracellular Domain: } \\
\text { Relation (\%) } \\
\text { to human } 1 \mathrm{~A}-2\end{array}$} & \multicolumn{2}{|c|}{$\begin{array}{l}\text { Extracellular Domain: } \\
\text { Relation (\%) } \\
\text { to human A-2 }\end{array}$} & \multirow[t]{2}{*}{$\begin{array}{l}\text { GenBank } \\
\text { accession } \\
\text { number }\end{array}$} & \multirow[t]{2}{*}{$\begin{array}{l}\text { Refer- } \\
\text { ence }\end{array}$} \\
\hline & & & & I & $S$ & I & $S$ & & \\
\hline IA-2 & $\begin{array}{l}\text { human } \\
\text { bovine } \\
\text { rat } \\
\text { mouse } \\
\text { zebrafish } \\
\text { Drosophila } \\
\text { C. elegans }\end{array}$ & $\begin{array}{l}2 \mathrm{q} 35 \\
- \\
- \\
1 \\
\text { LG9 } \\
2 \\
\text { III }\end{array}$ & $\begin{array}{l}979 \\
979 \\
983 \\
979 \\
357^{\mathrm{a}} \\
575^{\mathrm{a}} \\
767\end{array}$ & $\begin{array}{r}100 \\
99 \\
98 \\
97 \\
82^{\mathrm{a}} \\
58^{\mathrm{a}} \\
46\end{array}$ & $\begin{array}{r}100 \\
99 \\
98 \\
97 \\
87^{\mathrm{a}} \\
65^{\mathrm{a}} \\
60\end{array}$ & $\begin{array}{r}100 \\
84 \\
81 \\
81 \\
- \\
24 \\
24\end{array}$ & $\begin{array}{r}100 \\
85 \\
83 \\
83 \\
- \\
33 \\
33\end{array}$ & $\begin{array}{l}\text { Q16849 } \\
\text { AF075170 } \\
\text { Q63259 } \\
\text { Q60673 } \\
\text { AF190144 } \\
\text { AF126741 } \\
\text { AF126740 }\end{array}$ & $\begin{array}{l}{[1,2]} \\
{[8]} \\
{[13]} \\
{[5]}\end{array}$ \\
\hline IA- $2 \beta$ & $\begin{array}{l}\text { human } \\
\text { macaca } \\
\text { rat } \\
\text { mouse } \\
\text { zebrafish }\end{array}$ & $\begin{array}{l}7 q 36 \\
- \\
- \\
12 \\
\text { LG7 }\end{array}$ & $\begin{array}{c}986 \\
1013 \\
1004 \\
1001 \\
131^{\mathrm{a}}\end{array}$ & $\begin{array}{l}74 \\
73 \\
73 \\
73 \\
85^{\mathrm{a}}\end{array}$ & $\begin{array}{l}78 \\
78 \\
77 \\
77 \\
87^{\mathrm{a}}\end{array}$ & $\begin{array}{l}31 \\
31 \\
31 \\
31 \\
-\end{array}$ & $\begin{array}{l}37 \\
37 \\
36 \\
36 \\
-\end{array}$ & $\begin{array}{l}\text { U65065 } \\
\text { O02695 } \\
\text { Q63475 } \\
\text { P80560 } \\
\text { AF190145 }\end{array}$ & $\begin{array}{l}{[7,10]} \\
{[14]} \\
{[15,16]} \\
{[9]}\end{array}$ \\
\hline
\end{tabular}

(a) Partial sequence; (-) Not determined; (I) Identity; (S) Similarity

Drosophila, chromosome map position 21E-22A; Zebrafish, LG9, linkage group 9; Zebrafish, LG7, linkage group 7

gree of similarity to human $I A-2$. The longest cDNA clone, $y k 27 f 7$ (kindly provided by Dr. Y. Kohara), was completely sequenced in our laboratory. The sequence, $2610 \mathrm{bp}$ in length, contained an open reading frame encoding 767 amino acids (GenBank accession number AF126740). Comparison of the $C$. elegans amino acid sequence with that of human $I A-2$ showed a $46 \%$ identity and $60 \%$ similarity within the intracellular domain and $24 \%$ identity and $33 \%$ similarity within the extracellular domain (Fig. 1, Fig. 2 and Table 1). Further examination of the $C$. elegans amino acid sequence showed many of the structural features found in human IA-2 including a single highly conserved PTP-like sequence (aa 473-764) within the intracellular domain, a transmembrane domain (aa 400-423), two dibasic amino acids at positions 256-257 and a conserved cysteine motif at the $N$-terminus (aa 21-77). Chromosome mapping localized the $C$. elegans $I A-2$ gene to chromosome III corresponding to the B0244.2 gene locus (GenBank accession number U28971).

To see whether the $C$. elegans homolog of human $I A-2$ was expressed in neuroendocrine tissue and to study its expression dynamics, the putative promoter region of $C$. elegans $I A-2$, (3.2 kb upstream of ATG) was linked to the full-length coding sequence of $C$. elegans $I A-2(2301 \mathrm{bp})$ and the $G F P$ reporter gene and then introduced into $C$. elegans. Examination of transgenic animals showed expression of GFP exclusively in neuronal tissues and in particular in the ventral nerve cord, preanal ganglia, and in the nerve ring [21] (Fig.3). Expression was first observed during early embryonic elongation (1.5-fold stage) and continued through adulthood. A nuclear localized version of the reported gene (GFP linked to a nuclear localization signal under control of the $C$. elegans promoter) showed mosaic expression in ventral cord neurons (Fig.3). Examination of many animals showed that all neurons of the ventral nerve cord could express both reporter constructs, suggesting expression is pan-neuronal. Attempts to determine the function of $I A-2$ in $C$. elegans by injecting $C$. elegans $I A-2$ dsRNA into the gonads of adult hermaphrodites (RNA-mediated interference) to suppress $I A-2$ mRNA expression have not been thus far successful. Similarly, overexpression of $C$. elegans $I A-2$ cDNA, linked to heat shock promoter, failed to show a phenotype (unpublished data).

Drosophila. A search of the Drosophila database showed five ESTs that showed similarity to $I A-2$. Two of these clones (GenBank accession numbers, HL02546 and GH18155), obtained from Research Genetics, were sequenced in our laboratory and showed a partial sequence with an open reading frame of 575 amino acids containing a PTP intracellular domain (473 aa), a transmembrane domain (24 aa) and a portion of an extracellular domain (78 aa) (Figs. 1, 2). The intracellular domain was $58 \%$ identical and $65 \%$ similar to human IA-2, whereas the partial extracellular domain was $24 \%$ identical and $33 \%$ similar to the extracellular domain of human IA-2 (Table 1). Chromosome mapping localized the Drosophila IA-2 gene to Chromosome 2 map position 21E-22A corresponding to clone D844 (GenBank accession number, AC008228).

We investigated the embryonic expression dynamics of Drosophila IA-2 by embryo whole-mount in situ hybridizations $[17,18]$ using a riboprobe that covered the entire Drosophila IA-2 intracellular domain. During embryonic development $I A-2$ gene expression is restricted to a subset of CNS neurons (Fig.3). Expression is detected at embryonic stage 12 in neurons that flank the ventral cord midline and in a subset of neurons in the cephalic lobe. In addition to this zygotic expression, maternal Drosophila IA-2 

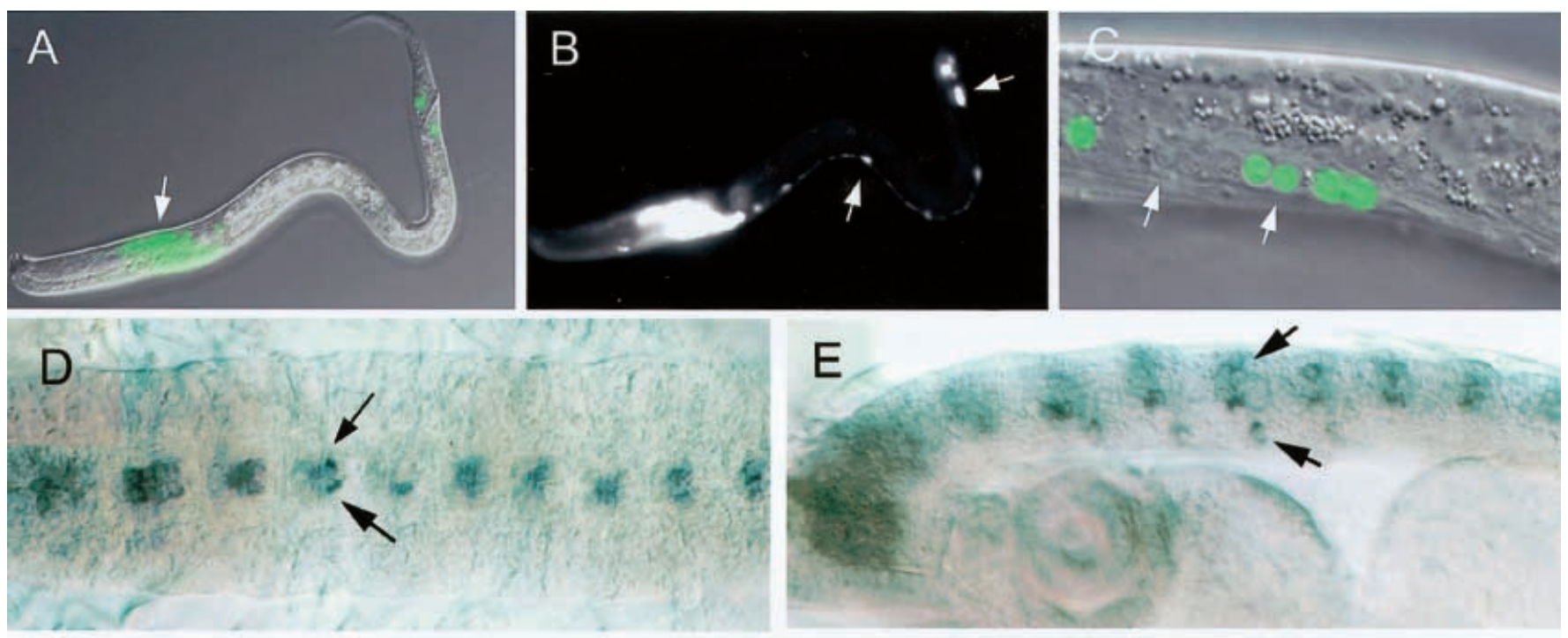
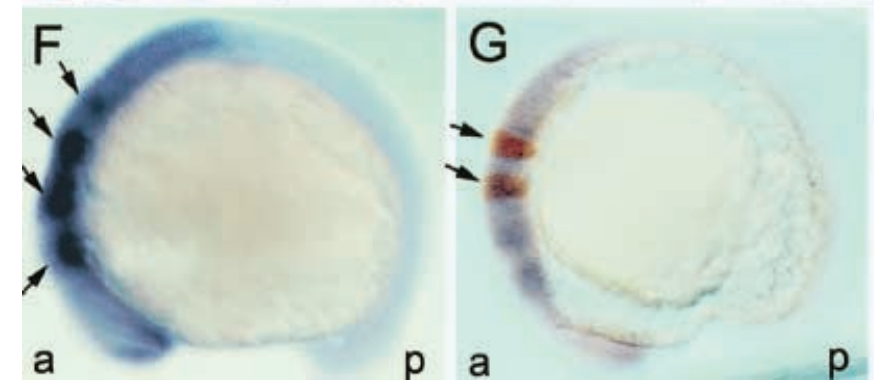

$\mathrm{H}$

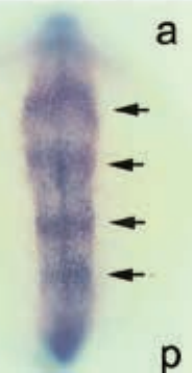

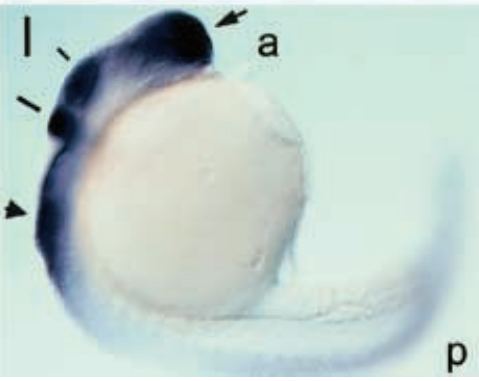

Fig. 3 (A-I). Expression of $I A-2$ in neural tissues. Upper panel: Localization by immunofluorescence of GFP ligated to the full length coding sequence of $C$. elegans $I A-2$ under control of the $C$. elegans $I A-2$ promoter. Larval expression pattern: A nerve ring (arrow); B ventral nerve cord and pre-anal ganglia (arrows). Panel $\mathrm{A}$ is a bright field image merged with false-colored fluorescence. Panel B is the fluorescent image alone. C: A nuclear localized version of the report gene illustrates mosaic expression in a cluster of five ventral cord neurons (between the two arrows) showing GFP expression in two, but not the other three neurons. D-E: In situ hybridization with a Drosophila riboprobe showing $I A-2$ expression in clusters of CNS neurons at stage 15 of development. (D, ventral view; E, lateral view). F-I in situ hybridization with zebrafish mRNA. Four distinct zebrafish $I A-2$ expression domains (arrows) in the anterior neural tube at the 15 somite stage (F and $\mathbf{G}$, lateral views; $\mathbf{H}$, dorsal view). Double staining with Krox-20 (orange) shows co-localization of $I A-2$ expression with rhombomeres 3 and $5(\mathbf{G})$. Expression of $I A-2$ in the anterior brain at 24 hours after fertilization (I, lateral view): telencephalon and anterior diencephalon (long arrow); tectum (short line); midbrain-hindbrain boundary (long line); hindbrain (short arrow); (a) anterior; (p) posterior

transcripts are observed in early cellular blastoderm embryos. Soon after cellularization, however, no expression is detected until stage 12 .

Zebrafish. The search for IA-2 homologs in zebrafish was carried out by screening a zebrafish cDNA library (adult whole fish) with a full length mouse $I A$ -
2 cDNA. We isolated a single positive clone and obtained a partial sequence which showed an open reading frame of 357 aa with an intracellular domain that was $82 \%$ identical and $87 \%$ similar to the intracellular domain of human IA-2 (Fig.1, Fig. 2, Table 1). A second homolog (accession number AI794337) was identified by searching the GenBank and an EST clone containing the identical sequence was obtained from Research Genetics. It was sequenced in our laboratory and it showed a short open reading frame of 131 aa with $85 \%$ identity and $87 \%$ similarity to the intracellular domain of human IA-2 (Table 1 ) but $92 \%$ identity and $93 \%$ similarity to the intracellular domain of IA- $2 \beta$, suggesting that this clone was more closely related to IA- $2 \beta$ than to IA-2. We mapped the $I A-2$ homolog to zebrafish linkage group 9 and the $I A-2 \beta$ homolog to linkage group 7 by using a radiation hybrid panel [20].

We examined the temporal and spatial expression of $I A-2$ mRNA in the zebrafish embryo by in situ hybridization [19] and detected $I A-2$ transcripts at the beginning of gastrulation. During gastrulation and early somitogenesis, the transcripts were observed ubiquitously at a low level. At the 15 somite stage, however, the $I A-2$ transcripts were expressed at a high level as four clearly delineated bands in the presumptive midbrain-hindbrain area (Fig. 3). Double in situ hybridization with the Krox-20 gene, a marker of hindbrain [22], showed that the two posterior bands coincide with rhombomeres 3 and 5 (Fig. 3). 


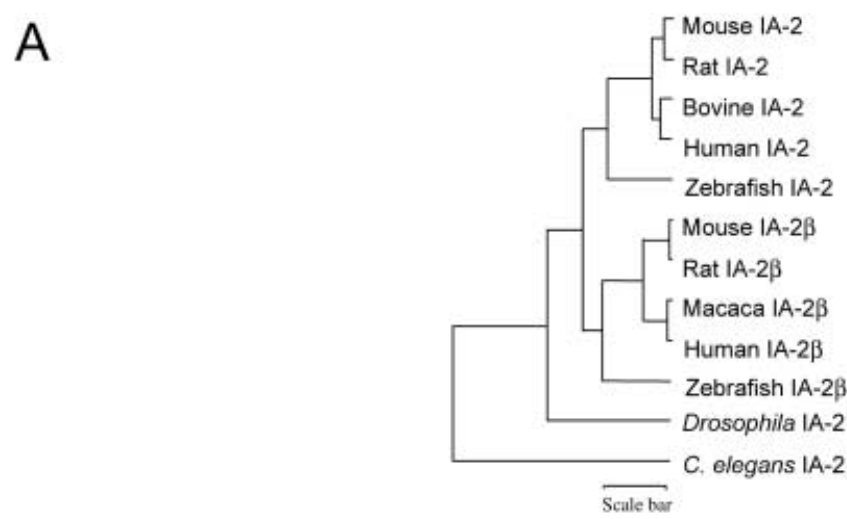

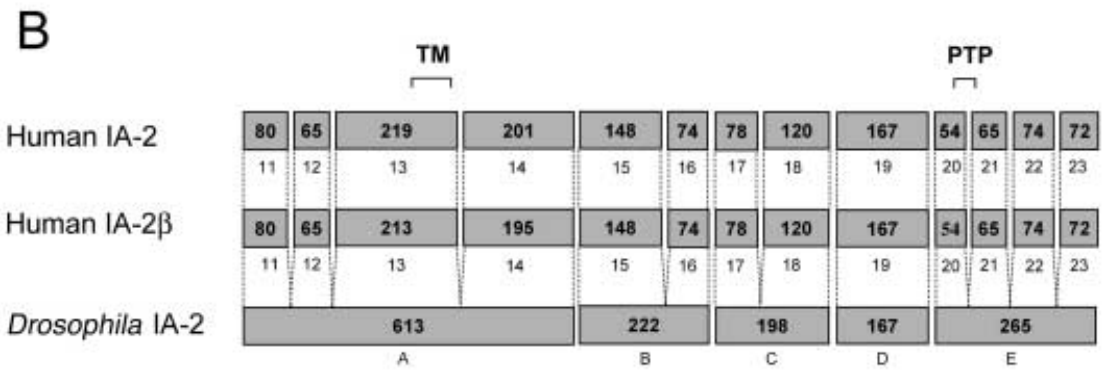

Fig. 4 (A-B). A Phylogenetic tree of the $I A-2$ family generated from nucleotide alignment. Accession numbers and references to the gene sequences used to establish the phylogenetic tree are given in Table 1 . The scale bar beneath the tree represents 10 substitutions per 100 residues. B Schematic representation of the organization of IA-2 genes. Each shaded box represents an exon and the number of nucleotides within the exon. The exons of human $I A-2 \beta$ are provisionally numbered to correspond to the exons of human $I A-2$. The letters beneath the Drosophila $I A-2$ exons are provisionally designated A-E. The last exon of human $I A-2$, human $I A-2 \beta$ and Drosophila IA-2 shows only the coding region and not the 3'UTR

At the 15 somite stage, the second from the anterior $I A-2$ expression domain was located adjacent to the midbrain-hindbrain boundary. Expression of $I A-2$ mRNA was observed in the entire brain and anterior part of the neural tube. A dramatic decrease was observed in the posterior part of the neural tube (Fig. 3). The $I A-2$ gene was expressed at high levels in the telencephalon, tectum, midbrain-hindbrain boundary and anterior part of the hindbrain $24 \mathrm{~h}$ after fertilization (Fig. 3). A similar expression pattern was found with zebrafish $I A-2 \beta$ (data not shown).

\section{Discussion}

The relation of $I A-2$ and $I A-2 \beta$ from different mammalian species to human $I A-2$ is shown in Table 1 and Figure 2. The intracellular domains of bovine, rat and mouse IA-2 are over $97 \%$ identical to human IA-2 (Table 1). The intracellular domain of macaca, rat and mouse IA- $2 \beta$ are over $98 \%$ identical to hu- man IA- $2 \beta$ (data not shown) but only $73 \%$ identical to human IA-2 (Table 1). Our findings show that the $I A-2$ and $I A-2 \beta$ genes belong to two distinct subgroups within the $I A-2$ family which is part of the larger PTP superfamily. The PTP relative that is closest to the IA-2 family is LAR which shows approximately $33 \%$ identity to the intracellular domain of IA-2 [23] (GenBank accession number NP002831). The PTP-like core sequences of IA-2 and IA- $2 \beta$, differ in several important ways from that of the highly conserved PTP signature motif (VHCSAGXGR S/T G) found in other members of the PTP family. In place of an alanine (A) at the fifth position, IA-2 has an aspartic acid (D) (Fig.2). Based on the three dimensional structure of other PTPs and site-directed mutagenesis, it is known that a substitution at this position can result in a loss of enzyme activity and, in fact, IA2 lacks enzymatic activity [4,6]. Human, bovine, rat, mouse and $C$. elegans IA-2 all have an aspartic acid in place of alanine at this position, whereas zebrafish IA-2 has an asparagine (N). Similarly, human, maca$\mathrm{ca}$, rat, mouse and zebrafish IA- $2 \beta$ have the same aspartic acid substitution. Only Drosophilia IA-2 maintains an alanine at the fifth position. At the tenth position of the PTP signature motif of human, macaca, rat, mouse and zebrafish IA- $2 \beta$, serine $(\mathrm{S})$ is substituted for threonine (T). Both Drosophila and C. elegans IA-2 differ in one other important aspect from the highly conserved PTP signature motif. They both lack a cysteine (C) at the third position which is known to be essential for PTP enzymatic activity [24].

Our findings suggest that $I A-2$ and $I A-2 \beta$ belong to an evolutionarily conserved gene family. The phylogenetic tree (Fig. 4A), generated by nucleotide alignment, illustrates the relations between members of 
this family. Moreover, based on the recently reported complete genomic sequences of $C$. elegans and Drosophila, it seems that in invertebrates the $I A-2$ family is represented by only a single gene. In contrast, in vertebrates, the finding of two members of the $I A-2$ gene family (i.e. $I A-2$ and $I A-2 \beta$ ), located on different chromosomes supports from an evolutionary point of view, a relatively recent event of gene duplication.

In terms of its genomic structure, human $I A-2$ consists of 23 exons [25]. The extracellular domain is encoded by exons 1 to 12 , the transmembrane domain by exon 13 and the intracellular domain by exons 14 to 23 . The genomic structure of mouse $I A-2$ is nearly identical to that of human $I A-2$ with 23 exons (unpublished data). Analysis of recent data from the $\mathrm{Hu}-$ man Genome Project showed a working draft genomic sequence containing the coding region of the intracellular domain of human IA- $2 \beta$ (GenBank accession number, AC005481). Identification of the putative intron-exon junctions showed that the genomic structure (Fig. 4B) of the intracellular domain of human $I A-2 \beta$ (chromosome 7q36) is nearly identical to that of human $I A-2$ (chromosome 2q35). The high relatedness between the structure of the Drosophila gene and that of human $I A-2$ and $I A-2 \beta$ suggests that they arose from a common ancestral gene. Comparing the cDNA of the intracellular and transmembrane domains of Drosophila IA-2 with its working draft genomic sequence (GenBank accession number, AC013239) showed a total of 5 exons (provisionally designated A-E) which share 4 identical intronexon junctions with the 13 exons of the intracellular and transmembrane domains of human $I A-2$.

Our study shows that $I A-2$ and $I A-2 \beta$ are subgroups of the $I A-2$ family and are evolutionarily related to genes in organisms such as C. elegans and Drosophila which are thought to have diverged over 500 million years ago. In the species examined, the $I A-2$ genes are expressed in neural tissues. The function of $I A-2$ genes is still not known but their lack of phosphatase activity is not unique among members of the PTP superfamily. The PTP-like molecules with STYX domains also lack phosphatase activity because of substitutions in catalytically essential residues [24]. It is thought that these evolutionarily-conserved PTP-like molecules have non-catalytic functions such as serving as decoys by stably interacting with PTP substrates and thereby preventing or delaying dephosphorylation by conventional PTPs, or by modulating downstream phosphatase-dependent signaling [24]. These possibilities have not yet been proven for IA-2 but because these molecules have been highly conserved over millions of years they must play an important part in the normal biology of the neuroendocrine system. The fact that these genes existed long before the development of the pancreatic islet of Langerhans, argues that on an evolu- tionary time-scale their role as autoantigens in Type I diabetes is a recent event.

Acknowledgements. We thank Dr M. Tsang for the chromosome mapping of $I A-2$ and $I A-2 \beta$ in zebrafish and Dr I. Dawid for helpful discussions.

\section{References}

1. Lan MS, Lu J, Goto Y, Notkins AL (1994) Molecular cloning and identification of a receptor-type protein tyrosine phosphatase, IA-2, from human insulinoma. DNA Cell Biol 13: 505-514

2. Notkins AL, Lan MS, Leslie RD (1998) IA-2 and IA-2 $\beta$ : The immune response in IDDM. Diabetes Metab Rev 14: 85-93

3. Lan MS, Wasserfall C, Maclaren NK, Notkins AL (1996) IA-2, a transmembrane protein of the protein tyrosine phosphatase family, is a major autoantigen in insulin-dependent diabetes mellitus. Proc Natl Acad Sci USA 93: 6367-6370

4. Leslie RD, Atkinson MA, Notkins AL (1999) Autoantigens IA-2 and GAD in Type I (insulin-dependent) diabetes. Diabetologia 42: 3-14

5. Lu J, Notkins AL, Lan MS (1994) Isolation, sequence and expression of a novel mouse brain cDNA, mIA-2, its relatedness to members of the protein tyrosine phosphatase family. Biochem Biophys Res Commun 204: 930-936

6. Magistrelli G, Toma S, Isacchi A (1996) Substitution of two variant residues in the protein tyrosine phosphatase-like PTP35/IA-2 sequence reconstitutes catalytic activity. Biochem Biophys Res Commun 227: 581-588

7. Wasmeier C, Hutton JC (1996) Molecular cloning of phogrin, a protein-tyrosine phosphatase homologue localized to insulin secretory granule membranes. J Biol Chem 271: $18161-18170$

8. Hermel JM, Dirkx R, Solimena M (1999) Post-translational modifications of ICA512, a receptor tyrosine phosphatase-like protein of secretory granules. Eur J Neurosci 11: 2609-2620

9. Lu J, Li Q, Xie H et al. (1996) Identification of a second transmembrane protein tyrosine phosphatase, IA- $2 \beta$, as an autoantigen in insulin-dependent diabetes mellitus: Precursor of the 37-kDa tryptic fragment. Proc Natl Acad Sci USA 93: 2307-2311

10. Li Q, Borovitskaya AE, DeSilva MG et al. (1997) Autoantigens in insulin-dependent diabetes mellitus: Molecular cloning and characterization of human IA- $2 A m \beta$. Proc Assoc Am Physicians 109: 429-439

11. Zhang B, Lan M, Notkins AL (1997) Autoantibodies to IA-2 in insulin-dependent diabetes mellitus: Location of major antigenic determinants. Diabetes 46: 40-43

12. Xie H, Zhang B, Matsumoto Y, Li Q, Notkins AL, Lan MS (1997) Autoantibodies to IA- 2 and IA- $2 \beta$ in IDDM recognize conformational epitopes: Location of the 37 and 40 $\mathrm{kDa}$ fragments determined. J Immunology 159: 3662-3667

13. Kambayashi Y, Takahashi K, Bardhan S, Inagami T (1995) Cloning and expression of protein tyrosine phosphataselike protein derived from a rat pheochomocytoma cell line. Biochem J 306: 331-335

14. LaGasse J, Jelinek L, Sexson S et al. (1997) An islet-cell protein tyrosine phosphatase is a likely precursor to the $37-\mathrm{kDa}$ autoantigen in type 1 diabetes; human and macaque sequences, tissue distribution, unique and shared epitopes, predictive autoantibodies. Mol Med 3: 163-173 
15. Fitzgerald LR, Walton KM, Dixon JE, Largent BL (1997) PTP NE-6: a brain enriched receptor-type protein tyrosine phosphatase with a divergent catalytic domain. J Neurochem 68: 1820-1829

16. Chiang MK, Flanagan JG (1996) PTP-NP, a new member of the receptor protein tyrosine phosphatase family, implicated in development of nervous system and pancreatic endocrine cells. Development 122: 2239-2250

17. Kambadur R, Koizumi K, Stivers C, Nagle J, Poole SJ, Odenwald WF (1998) Regulation of POU genes by castor and hunchback establishes layered compartments in the Drosophila CNS. Genes Dev 12: 246-260

18. Mellerick DM, Kassis JA, Zhang SD, Odenwald WF (1992) Castor encodes a novel zinc finger protein required for the development of a subset of CNS neurons in Drosophila. Neuron 9: 789-803

19. Toyama R, Dawid IB (1997) Lim6, a novel LIM homeobox gene in the zebrafish: Comparison of its expression pattern with lim1. Dev Dyn 209: 406-417
20. Hukriede NA, Joly L, Tsang M et al. (1999) Radiation hybrid mapping of the zebrafish genome. Proc Natl Acad Sci USA 96: 9745-9750

21. Park M, Krause MW (1999) Regulation of postembryonic $\mathrm{G}(1)$ cell cycle progression in Caenorhabditis elegans by a cyclin D/CDK-like complex. Development 126: 4849-4860

22. Oxtoby E, Jowett T (1993) Cloning of the zebrafish krox-20 gene (krx-20) and its expression during hindbrain development. Nucleic Acids Res 21: 1087-1095

23. Nam HJ, Poy F, Krueger NX, Saito H, Frederick CA (1999) Crystal structure of the tandem phosphatase domains of RPTP LAR. Cell 97: 449-457

24. Wishart MJ, Dixon JE (1998) Gathering STYX: Phosphatase-like form predicts functions for unique protein-interaction domains. Trends Biochem Sci (TIBS) 23: 301-306

25. Xie J, Zhang B, Lan M, Notkins AL (1998) Genomic structure and promoter sequence of the insulin-dependent diabetes mellitus autoantigen, IA-2. Genomics 54: 338-343 